\title{
Panel
}

\section{The Relationship between CS Education Research and the SIGCSE Community}

\author{
Michael Goldweber (Moderator) \\ Xavier University \\ mikeyg@cs.xu.edu \\ Sally Fincher \\ University of Kent at Canterbury \\ S.A.Fincher@kent.ac.uk
}

\author{
Martyn Clark \\ University of Leeds \\ martyn@comp.leeds.ac.uk \\ Arnold Pears \\ Uppsala University \\ arnoldp@docs.uu.se
}

Categories and Subject Descriptors: K.3.2 [Computers and Education]: Computer and Information Science EducationComputer Science Education

General Terms: Measurement, Experimentation

Keywords: CS Education Research

\section{SUMMARY}

The nature of the SIGCSE Symposium has seemingly evolved over the past ten years. Ten years ago the typical Symposium paper focused on the sharing of someone's interesting or innovative idea on some aspect of the teaching component of being an undergraduate CS instructor. This could be a pedagogic technique, a "nifty" assignment or even the use of a lecture prop. It was also a primary source for the dissemination of courseware to support CS education (CSEd). The annual gathering at the Symposium was in many respects a large idea swap meet.

The most recent Symposia have become infused with the notion of assessment; not techniques for the assessment of students and learning outcomes, but the assessment of the ideas or techniques being presented at the conference. It is seemingly no longer sufficient to develop an interesting or innovative technique/courseware/pedagogic approach, it must also be, using the tools of CSEd research, formally assessed.

This panel seeks to explore this phenomenon by examining different perspectives on the question of the relationship between the SIGCSE community in general and the Symposium in particular and formal CSEd research.

\section{MICHAEL GOLDWEBER}

The questions regarding the relationship between CSEd research and the SIGCSE community are:

- What is the purpose of the SIGCSE community?

- What is CSEd research and who is qualified to undertake CSEd research?

- Are SIGCSE sponsored conferences the appropriate forums for the dissemination of CSEd research?

- Is CSEd research a necessary component for Symposium paper acceptance?

The SIGCSE mission statement provides a concise explanation of the purpose of the SIGCSE special interest group.

Copyright is held by the author/owner

ITiCSE'04, June 28-30, 2004, Leeds, United Kingdom.

ACM 1-58113-836-9/04/0006.
The definition of what is CSEd research and who is qualified to undertake such research is addressed below.

Regarding the appropriateness of the SIGCSE conferences for the dissemination of CSEd research: There is no doubt that well conducted CSEd research can inform the SIGCSE community, but is the CSEd community equipped to recognize what is and what is not well conducted CSEd research? For many in the SIGCSE community their training (doctoral) not only excluded education research, it probably did not cover the basics of undergraduate teaching.

Furthermore, given the intellectual "swap meet" that is the Symposium, most attendees act (with wisdom or otherwise) as their own filter for the worthiness to them of a presented topic. Anecdotal evidence suggests two outcomes; formal research supporting what a Symposium attendee believes is worthwhile is "preaching to the choir." (ex. The utility of algorithm visualization tools.) Formal research contradicting what a Symposium attendee believes is worthwhile is either deemed flawed, inconclusive (i.e. additional research is called for), or simply ignored. (ex. Research indicating that the use of robotics in CS 1 does not improve student outcomes has not dampened adopters enthusiasm for the technique: even on the part of the researcher [3].)

Finally, while no formal requirement exists that submitted Symposium papers possess a CSEd research component, the perception that such will improve one's chance for acceptance is growing. Is the SIGCSE community endeavoring (consciously or unconsciously) to increase the respect that scholarship within the community holds with tenure boards? Regardless of the reason(s), such a shift would not only be dangerous (the undertaking and possible eventual community acceptance of flawed CSEd research) but would deprive the CSEd community with the valuable intellectual swap meet that has marked the Symposia of the past.

\section{MARTYN CLARK}

An easily overlooked fact about universities is that they tend to be organized according to subject matter. However, the independence within the academy symbolized by disciplinary status is an important means of acknowledging the validity of a particular study. Further, anyone who has attempted interdisciplinary work learns quickly the importance of disciplinary context.

Discipline as a concept is difficult to encapsulate [1]. Nevertheless, a working definition might emphasize that disci- 
plines, in addition to owning a particular set of theories and concepts, have distinct ideas about what constitutes knowledge, what constitutes a worthwhile research problem and how knowledge claims should be presented and evaluated [2]. Procedures for adding to the stock of disciplinary knowledge involve review by domain specialists. Further, current understandings of particular domain specific issues and concerns may be considered in terms of the understandings and beliefs of key individuals within the relevant community.

I will argue that, in general, research into teaching and learning draws upon and contributes to the body of knowledge owned by the discipline of education. The education research community is probably not well equipped to evaluate new knowledge in, say, networking. However, new knowledge claims which derive from and contribute to understanding in teaching and learning must, like all research claims, derive their value from being accepted by the relevant disciplinary community. That is, anyone making a new knowledge claim in this area must submit their idea for evaluation by the education community.

\section{ARNOLD PEARS}

CSEd research publications can be classified as, descriptive/anecdotal, scientific experimental and multi-disciplinary. Each type of contribution is of value, though they are focussed on different aspects of the domain and vary in their relevance to other educators.

CSEd researchers play a vital role in the development of relevant and innovative systems of education. It is vital that they should be CS professionals, with skills in other relevant disciplines, who are capable of identifying key teaching and learning issues unique to the field, then focusing meaningful research on them.

The key contribution of CSEd researchers is their ability to illuminate domain specific teaching and learning issues in CS. By selecting relevant educational research and applying this to CS developing practical insight, and new approaches to teaching and learning can be achieved in a way that is specifically tailored to the CS education domain.

In short, CS domain expertise is vital to success! We need to establish a common understanding of the role of the SIGCSE and ITiCSE communities in defining the scope and focus of CSEd research. A research framework seems a fundamental first step towards this goal, and will help us to interpret and structure the future of CSEd research, both within the CSEd community and the wider interdisciplinary community of which CSEd research is a part.

\section{SALLY FINCHER}

There are two particular issues that affect the perception of, and participation in, CSEd research.

The first is the relationship between phenomena and evidence (or why CSEd research is about research, not about teaching) the second is the nature of the interdisciplinarity of the field (or an answer to the complaint if CSEd research is research, then it's not CS).

Phenomena and Evidence: One can illustrate the problems of phenomena and evidence with an example from medical history. Edward Jenner (1749-1823) was a doctor in rural England. He noticed that people who worked closely with cattle and had caught a mild cowpox infection from them did not get smallpox, at that time a deadly disease. Jenner compiled extensive case studies to learn if this was indeed the case. He found that this was so, and went on to invent the process of "vaccinating" people from smallpox[4].

What is the epistemological status of his case studies? Are they simply recording a phenomenon that happens in the world anyway, whether we can see it or not? Or do the compilations provide evidence of the very existence of something only previously theorised about? ("There is a relationship, not between specific people and circumstances, but between these diseases.")

To date much of what is published as CSEd (called "research" or not) has been concerned with noticing phenomena: "This is what happens when I teach $x$ in this way." What moves recognition of phenomena to evidence is purposeful investigation and a relationship to theory.

If we want to move from "infecting my patients with cowpox stops them getting smallpox" to recognising that "denatured viruses can be used to trigger an immune response in advance of being infected by lethal strains of a complete class of diseases", then we need to go beyond "this works for me" to draw upon - even develop - theories of action, and report studies designed to illuminate them.

Nature of Interdisciplinarity: "Computer Science" is itself a new discipline, created out of many others. The debt to mathematics is clear. Theoretical CS, Algorithms etc., all use mathematical methodology. Hardware interfacing is clearly akin to EE, while software engineering methodologies have come into academia from a variety of sources.

CSEd research is also informed by other disciplines - much theory is from education and the learning sciences: experimental and analysis techniques are drawn widely; from statistics to empirical studies to social science methodologies such as ethnography. In this way its development has been similar to many of the other research areas within CS which have developed from other subjects.

The key to viewing CSEd as a distinct area must surely be in the questions that we ask. If the questions asked are generalist, ("Do students learn better from face-to-face or Webbased interaction?") or facile ("Do students learn better if $A$ or $B$ is their first programming language?") then perhaps there may be descriptive classroom studies written, perhaps there may be more pedagogic environments and visualisation tools built, but perhaps what we are doing (although valuable) is not CSEd research.

But if we ask questions that can only be addressed from within CS: "Does a knowledge of architecture make more expert programmers?" or "Does student understanding of programming concepts differ with language of first instruction?" then these questions cannot be addressed by someone outside of CS. What meaning would such questions have to someone who could not program? Who did not understand what the quality of the relationship between, say, functional and OO programming and its import for first instruction?

CSEd research is new, co-existing in places with other sorts of publications. Where it starts and stops is not yet clear. But everything was once emergent, including CS. That's not an argument to say it doesn't belong.

\section{REFERENCES}

[1] T. Becher. Academic tribes and territories. SRHE/Open University Press, Buckingham, 1989

[2] M. Clark. Computer science: a hard-applied discipline? Teaching in Higher Education, 8:72-87, 2003.

[3] B. Fagin. Measuring the effectiveness of robots in teaching computer science. In 34th SIGCSE Symposium on CS Education, 2003.

[4] E. Jenner. An inquiry into the causes and effects of the variolae vaccinae, 1978. 